\title{
Thormation
}

Nordic Journal of Art and Research

ISSN: 1893-2479

$\underline{\text { www.artandresearch.info }}$

\section{The making of $F Q$, or how to pick up pellets of information in the clouds of fantasy.}

\author{
Kristin Bergaust $^{1}$ \\ Oslo and Akershus University College of Applied Sciences
}

\begin{abstract}
In an attempt to look at how content could be developed in dialogue with the use of visual documentary material, this article traces key ideas and references that were important to the making of an animation "FQ". A research blog, personal notes and references are used to reflect on the work. The animation was based on historical portraits of the Norwegian political pioneer, Fredrikke Marie Qvam (1843-1938), and created for outdoor screening in the main square in her home town. Research and documentary material formed a base for an animation that was conceptually inspired by photo theories from diverse sources as well as feminist film theories of the gaze. In the process, imagination and fantasy plays into the treatment of the documentary material while the local viewing situation anchors the work in a biographical context.
\end{abstract}

Keywords: artistic research, animation, contemporary art practice

\begin{abstract}
Although photographs are certainly artifacts, in a world littered with photographic relics, their appeal is that they also appear to have the status of found objects unpremeditated slices of the world. As both clouds of fantasy and pellets of information, they trade simultaneously on the prestige of art and the magic of the real (Sontag, 1990 p. 69).
\end{abstract}

Writer and critic Susan Sontag's reflection was from before the digital photograph travelled the Internet across the diverse platforms we currently access. Nonetheless, as she points to found images as transporters of a potential to combine information inherent in the photographs, with a creative process of adding meaning through research and fantasy, her thoughts seem actualized today. In 2012, I made a video film work, titled " $F Q$ ", based on the Norwegian political pioneer feminist, Fredrikke

${ }^{1}$ Department of Art, Design and Drama, Oslo and Akershus University College of Applied Sciences, PB 4, St. Olavs Plass, N-0130. E-mail: Kristin.Bergaust@ hioa.no 
Marie Qvam (1843-1938). Aiming for something that also encompassed clouds of fantasy, I began the four-minute animated video projection with biographical material and eight portrait photographs. In the following, I will look at how the main ideas in the construction and content of the work were developed. What does historical or documentary material represent as a basis for artistic work? What impulses and references informed the process and how did this influence the content and mediation of the work? To facilitate this process, I employed a research blog (http://kbergaust.wordpress.com/), where I kept some of the material that informed my work process, as well as my notes, some of the theory that I was inspired and supported by, and finally, my reflections after having presented the work.

\section{Fredrikke Marie Qvam - her life and times}

The protagonist of my $F Q$ project was born by the name of Fredrikke Marie Gram in 1843 into an economically and culturally privileged family. The Gram siblings received an equal education, regardless of gender, and enjoyed an upbringing on the family farm near Steinkjer, where they were allowed to be physically active. Fredrikke eventually married her teacher, the lawyer Anton Qvam, who shared her strong political interests and radical views. Anton was an active politician within the liberal party (Venstre). Because of his political radicalism, his career was sometimes difficult. Nonetheless, he served for several terms as a member of the government, and even as prime minister, at that time seated in Stockholm, Sweden. He did not however live to see the Norwegian independence from the union with Sweden in 1905, as he died in 1904.

In 1896, Fredrikke Marie Qvam founded The National Health Organization for Women (NKS, Norske kvinners sanitetsforening). Her privileged position did not prevent the loss of four of her five children; one was still born, two died at an early age, and her son died from tuberculosis at the age of 25. She is quoted as having said that she would do everything she could to prevent this from happening to other mothers. Through a national network of women who devoted time and energy to fund-rising and volunteer work in their local communities, NKS organized practical measures such as free health check-ups for infants and children, education for nurses, and funding for hospitals and other institutions. Qvam led NKS with tremendous commitment until 1933, when she stepped back at the age of 90 years. NKS initiatives influenced health care policy, as we know it in Norway today. Engagement in the fundamental political issues of her times, such as the right to vote for women, also led Qvam to co-found Landskvinnestemmeretsforeningen (National Women's Suffrage Association), an organization advocating full democratic rights for all women, regardless of economic and social status. In 1903, she was also crucial in collecting 300,000 signatures from Norwegian women in support of Norwegian independence from the union with Sweden. After years of conflict and the danger of violent confrontation, the union was peacefully dissolved in 1905. 
Although the challenges of social and political change at the turn of the century must have been immense, Fredrikke Marie Qvam appears to have been an extremely practical and energetic person, with considerable political interest and influence. Ironically, since full voting rights for women were not fulfilled until 1913, for most of her life, she was without full democratic rights. Nonetheless, Qvam was known to be a strong lobbyist, her nickname, "Queen of the Corridors", referred to her strategy of influencing politicians through their wives. "All threads are collected in the hands of Mrs. Qvam", is another citation expressing her power (http://www.sanitetskvinnene.no/no/om_nks/historikk/fredrikke_marie_qvam).

\section{Background of the project}

So what was my motivation to create a work of art based on Fredrikke Qvam? I was commissioned to make a projection to be shown on a modernistic church façade, in the town square of Steinkjer, at the opening of Hilmarfestivalen in November 2012. Although I was free to introduce any theme for the work, I soon learned that Qvam, a pioneer in the women's movement, had lived most of her life in Gjævran, a farm near this small town in Nord-Trøndelag, Norway. I had already considered her portraits in connection with a plan to develop and expand an earlier work Empire, an installation based on historical portrait photographs of British royal women (http://www.kristinbergaust.no).

Working with Fredrikke Qvam, as a subject, meant that I was entering the realm of nineteenth century studio portraits once again; this time though, it was from the perspective of looking for signs of this individual as a person, of her outstanding personal strength and willpower, rather than the characteristics of the staged beauty of royal women.

I began the production process by exploring the life and times of Fredrikke Qvam. Biographical material, research on other historical factors, and the context of the presentation of the work, were all elements that influenced how the project was finally manifested. In learning that the 100-year anniversary of women's full right to vote would be in 2013, the historical and contemporary times became intertwined on a level of discourse pertaining to women's rights. This was a propitious coincidence, which felt like a confirmation of my idea to work with Fredrikke Marie Qvam.

\section{Collecting material: potentials}

Following on my former interest in the staging of women in photography and other image technologies, the project was developed as an animation, a collage of elements of portrait photographs, drawing, and animation. Museum director and writer Michael Rush notes that animation "has ignited a new interest among artists" (Rush, 2007 p. 237) and attributes this to new technical possibilities. However, the freedom of animating collages of still images has been part of the art field from the time of the nineteenth century experimental films, such as the cubist Fernand Léger's Ballet mécanique, 
from 1924, and the early Dadaist film Le retour à la raison by Man Ray, from 1923. Sometimes combined with photographs or acted scenes, animations in the art field have also been dealing with historical subjects, as can be seen in William Kentridge's influential work where coal drawings are the basis of animations that relate to the recent South African history of apartheid. Although shot on film, they are presented as video installations. Pipilotti Rist freely layers and colors her videos, often in a floating movement. Recently, her works have been projected in designated spaces, such as in her MoMA exhibition in 2010. While Rist's work is perhaps not perceived as animation, it includes the manipulation of color, speed, movement, and layers of images.

My first idea for the commission in Steinkjer was to make a simple, graphic animation, adjusted to float over the strong modernistic façade, a large wall that consisted of rectangular concrete profiles. First, finding good quality photographs of Fredrikke Qvam was critical. After exploring different sources, I chose the on-line collection of portraits in the The Norwegian National Library, as a starting point. Browsing through photographs from Qvam's era triggered an interest in photo theory, as a means of producing the ideas for treating the images. Transporting portrait photos into other media and situations, earlier readings of photographs, and uncovering their potential meaning, helped me to re-read and articulate the material at hand. Examining the images, arranging them in groups, and placing them in time, I attempted to read the photographs as visual expressions of a special life of extreme energy and the willpower to transform society and the environment for the better. How could archived portrait photos be used to create an artistic reflection on such an extraordinary woman? Today, Qvam, as a political force, an organizational talent, and a social innovator of her time, becomes visible through authentic biographical and historical research. Nonetheless, her portraits do not bear evidence to these achievements per se; they are neither monumental nor expressive in how they are staged. They seem private, but not intimate. Except for the earliest portrait in the checked dress, her personality does not come through. In the last two, she poses as a confident and experienced woman of achievement. However, in working with the portraits, I noticed a directness in her glance, a gaze at the camera. 


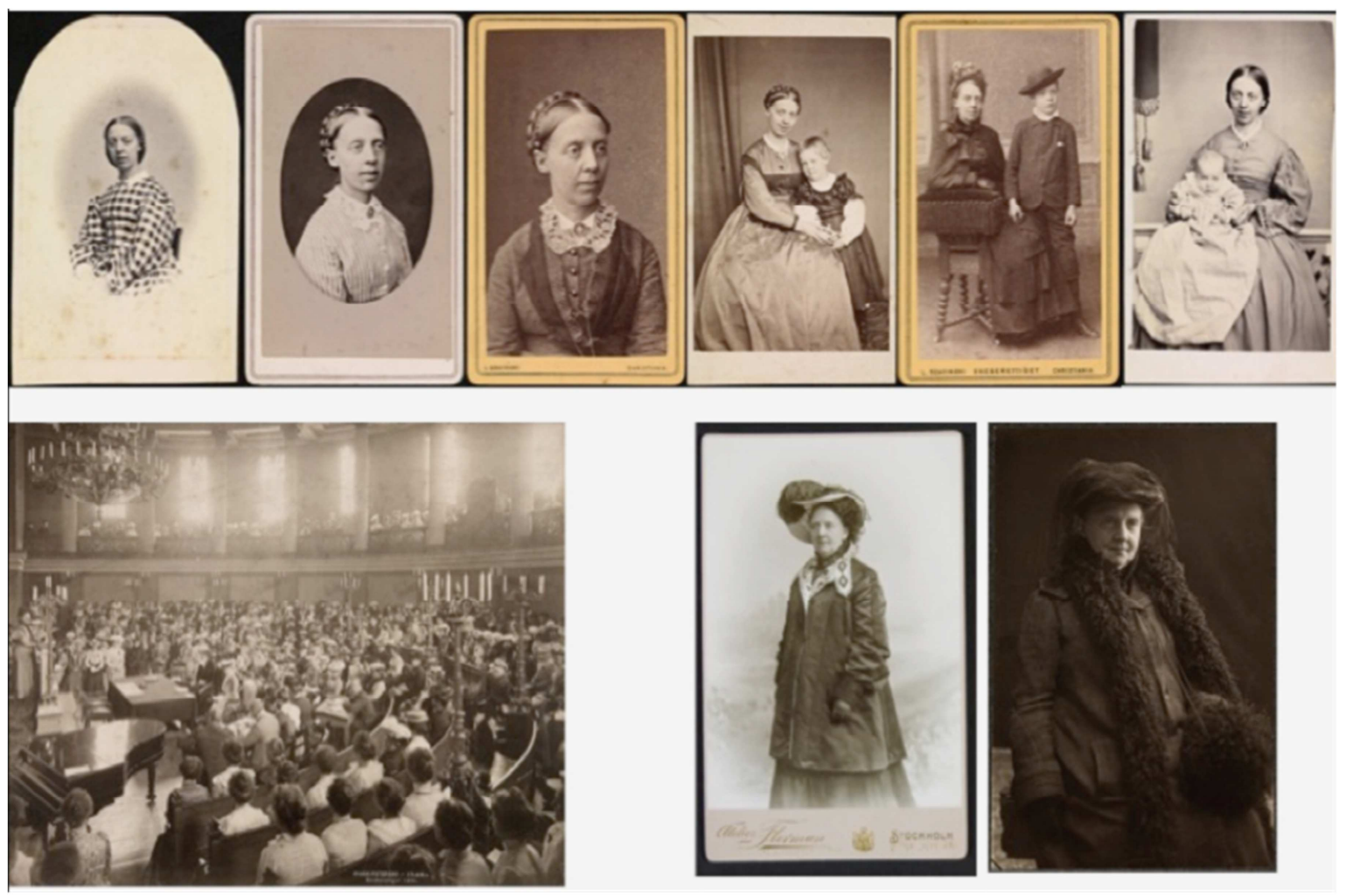

The photos that comprised the material for FQ

At this point, I was not entirely convinced of the possibilities; the material was meager, limited to eight portrait photographs and some additional photographs of larger groups connected to various events and functions of the many organizations with which Fredrikke Marie Qvam had been involved. Nonetheless, at certain points throughout her life, she had posed before a range of different cameras and the images are all dependent on her existence in time and space. Indeed, the portraits are fundamentally dependent on the historical existence of Fredrikke Marie Qvam and, as such, an obvious point of connecting to what she was. As Barthes maintains, "The photograph is literally an emanation of the referent" (Barthes, 1993 p. 80).

The portraits were transported from their origin as physical objects, digitized archival files, to what Stephen Bull terms "transient photography" (Bull, 2010 p. 28). This can characterize the digital photography of our time in general. He sums its meaning in three characteristics:

- in transition: always easily open to manipulation

- in transit: transmittable, mobile, and viewed on screens

- in a transient state: ephemeral, inherently erasable, and it can be destroyed with little physical effort

Bull further states that since it involves writing or drawing with light directly and it does not need to be printed on a fixed surface, in some ways, the transient can be seen as a truer version of the photographic medium. My project would realize a transient potential in the portraits; through this process, the content could emerge in new ways of presenting and seeing a material otherwise fixed in 
an archival format. The transient state represented a freedom in the treatment of the archived portraits, which allowed for actualizing content that was not inherent in the images themselves, something synthesized from biography rather than adapted to historical narrative.

Roland Barthes notes that four image-repertoires intersect in the portrait photograph; they can oppose and distort each other. He maintains, "In front of the lens, I am at the same time: the one I think I am, the one I want others to think I am, the one the photographer thinks I am, and the one he makes use of to exhibit his art." (Barthes, 1993 p. 13) To adopt the two positions of the photographer seemed fruitful: to imagine the person that my subject might have been while retouching and animating, admitting to making use of her, and then let the rendering of the subject travel through layers of transient interpretations.

\section{Preparing a visual logic: initial ideas}

In developing the project, I allowed myself to be inspired by the context of both the photographs and the rendered images and approach the photographs as complex visual communication. The portrait studio aesthetics were visibly present in the material: In the framing, the backgrounds, and the photographer's signatures, these photographs of variable quality are all formal poses arranged artfully in the studio, reminiscent of earlier portrait painting. This called for a look at other representations of women in the times of Fredrikke Qvam. Looking at popular culture, such as fashion and music, from around the beginning of the twentieth century, I needed insights in addition to the biographical and historical facts. Some of the elements I found were included in the project as a fashion shoot of a woman showing a hat and dress, and a few sounds from popular music.

Art historian Charles Merewether explains, "The archive, as distinct from a collection or library, constitutes a repository or ordered system of documents and records, both verbal and visual, that is the foundation from which history is written" (Merewether, 2006 p. 10). To adapt this for my own use, I constructed an archive, as was necessary, to "write the history", represented in the blog. There, I collected information about Fredrikke Marie Qvam's contemporaries, the international suffragette movement, such as the Pankhurst women. I was searching for visual manifestations of the suffragette movement, to see whether I could find graphic references that I could work with, when I discovered that Sylvia Pankhurst was an artist, and had created a logo with the symbol of an angel carrying a banner saying "freedom". I added red lines to see the main design more clearly. This led to my treatment of the only group image that I included in $F Q$; in my rendition, the small figure to the left flies up and becomes the older Fredrikke Marie Qvam. 


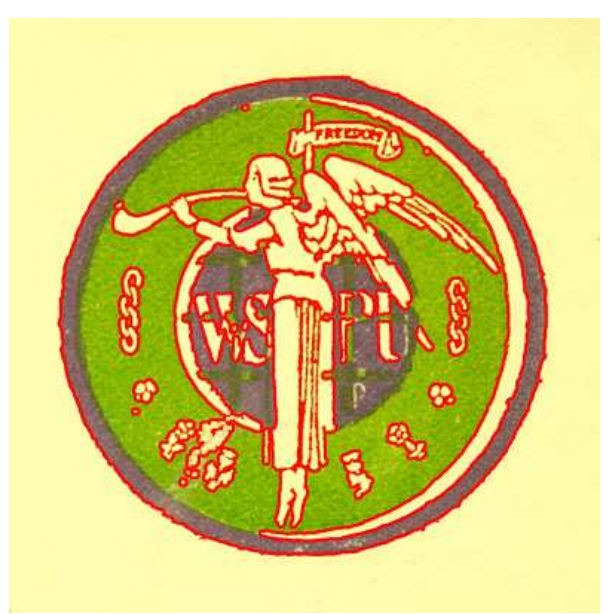

Logo by Sylvia Pankhurst, enhanced by Kristin Bergaust.



Still from $F Q$

The background photograph is a technically and aesthetically well-made overview of a Nordic conference held in Oslo University in 1902. Fredrikke Marie Qvam is the speaker; the space around her is filled with an audience of men and women; they fill the space in a rhythmic pattern that continues up under the roof where light is pouring in. Elaborate candelabra, with curved ornaments, and long white candlesticks that attract the eye, punctuate the space; a round ceiling lamp picks up the curved shape of the room. The image carries such optimism and unity in its composition and formal qualities; the historical event points toward a future of achievement. This photograph was included in $F Q$ to represent the wider society of humans, who were fundamental to all of Fredrikke Marie Qvam's efforts to better the conditions in society.

In earlier works, I regarded my transient processing of photographs as a practice akin to retouching, as it was done by hand in the darkroom by scraping or manipulating the glass negatives or directly as paint or drawing on prints in portrait studios in the nineteenth century. Continuing from this historical lineage of imaging crafts, I employed the atmosphere and chemical processes of the darkroom, as a universe, to help conduct my investigations and treatment of the portraits: The darkness, the red lights, the shifts between positive and negative, the flexibility of the contrasts, the enlargements, and the silver grains of the copy. In short: I worked out a visual logic into which my project could enter. This logic, along with the concepts of transient photography (Bull, 2010) and Barthes' description of the four intersecting image-repertoires (Barthes, 1993), forms a foundation for the artistic work and the practical choices in production. 


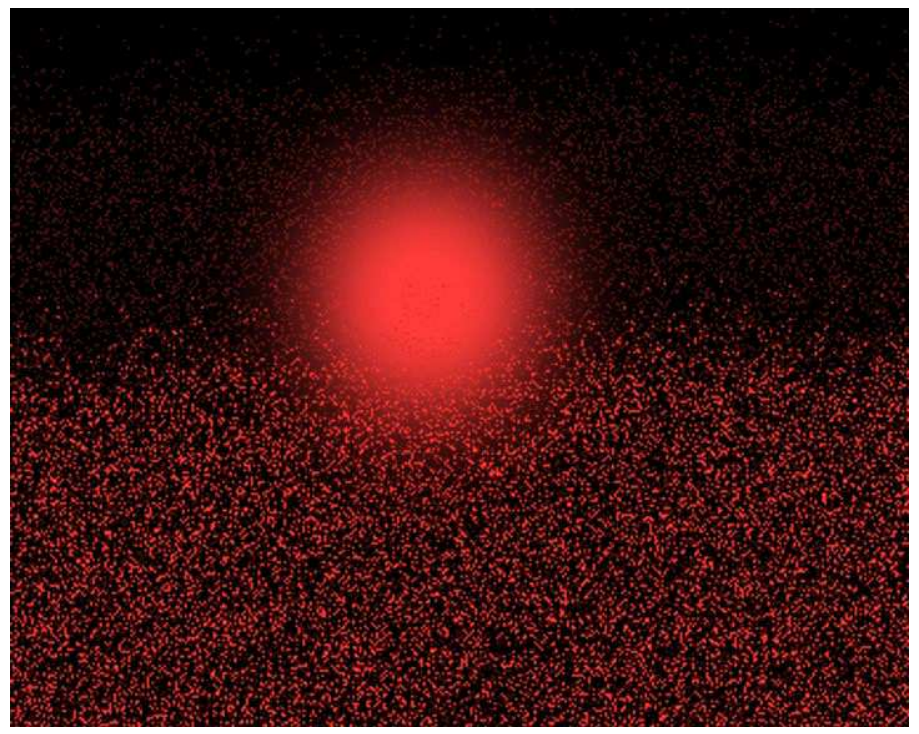

\section{Hands-on: conceptual development}

The first hands-on experiments with the material gave me additional thoughts on how to continue with the project; these ideas came from experiencing the photos by changing them, rather than just looking. The subject seemed to have an unconventional tendency to open her mouth while posing; she also had a look about the eyes that I found arresting. The image of Qvam as a young girl in a checked dress first drew my attention, the loud dress, the open mouth, and a challenging gaze let a personality shine through the black and white overexposed image. I made the contrasts and the graphic feel of the dress stronger, and then attempted to shut her mouth by retouching or redrawing parts of her face.
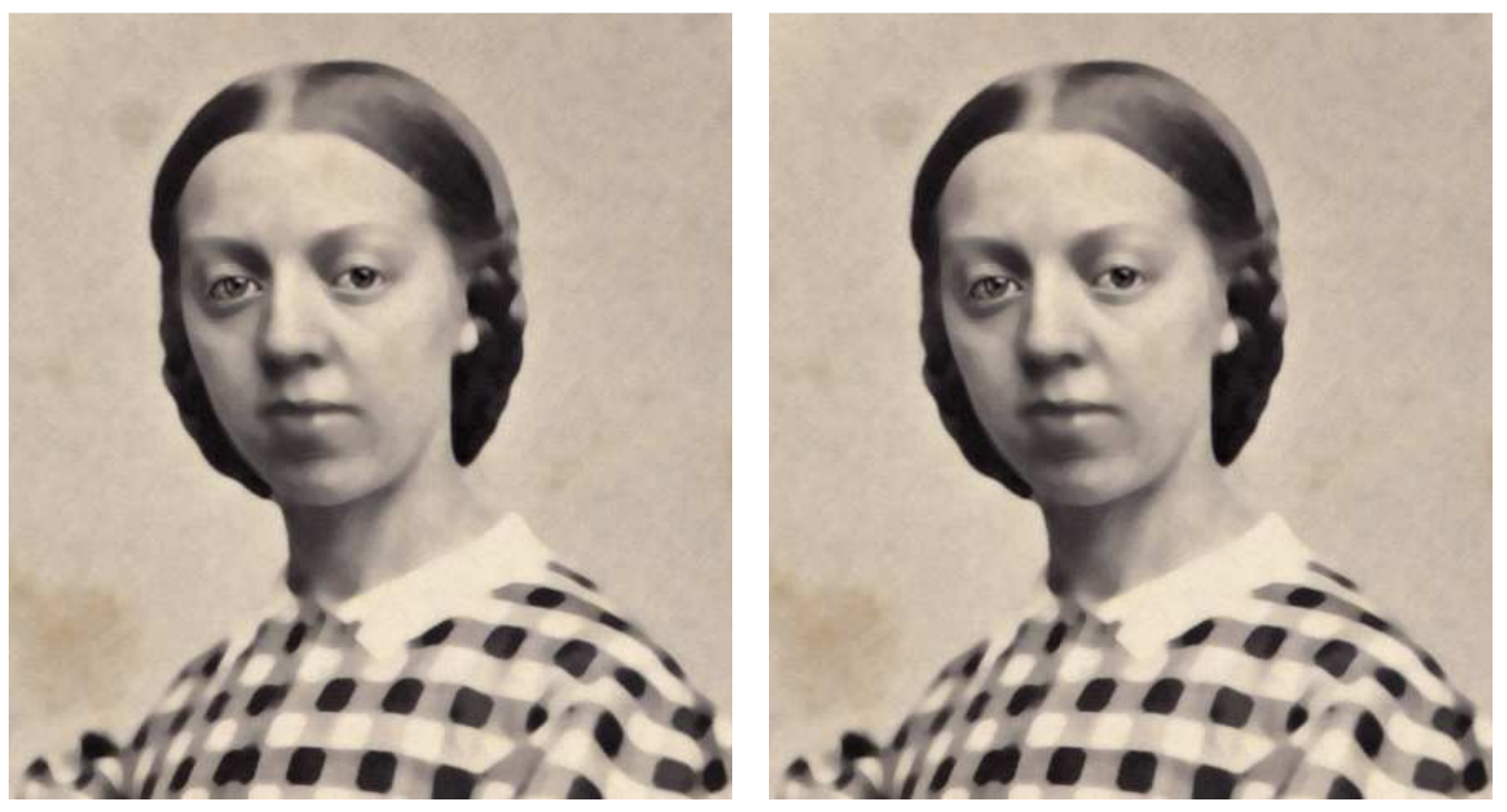
In the process, I found that the overall graphic treatment of the image had weakened her direct gaze, as can be seen in the left image. By reinstalling the eyes from the original photo, I got a result looking back at me, as can be seen on the right. As my fascination with the open mouth grew in this first attempt at a hands-on strategy, I thought of the concept of punctum, as developed by Roland Barthes in writing about looking at photographs in Camera Lucida. He says, "A photograph's punctum is that accident that pricks me (but also bruises me, is poignant to me)" (Barthes, 1993 p. 27). The punctum is something that cannot be named, frequently a detail that pricks you about a photograph, an addition, something that punctuates you emotionally or charges the photograph with something other than its studium, which could, for example, be its coded historical and political interest. Punctum is not merely about the detail, it is also about the time. "This punctum, more or less blurred beneath the abundance and the disparity of contemporary photographs, is vividly legible in historical photographs: there is always a defeat of Time in them: that is dead and that is going to die" (Barthes, 1993 p. 96). This points to a melancholic intensity in handling historical photographs; in this case, the biographical facts of the loss of the subject's children became overwhelming. While it is not always clear which children we see in the portraits, only one of them survived their mother. In looking at photographs, the punctum can be expanded to be seen as an influence on the working process with the transient photo. In this sense, experiencing the open mouth and experimenting with closing it, was the project's punctum, a point in the artistic process that created a breach where I could establish a dialogue with the material. At this point, it was not exclusively questions about visual choices, but about how the content could develop in dialogue with the visual. The portrait in the checked dress demonstrated the importance of both the gaze and the will represented in the open mouth, now shut. In terms of animation, the two positions of the mouth mean that she can be made to be seen speaking. However, I was looking for a way to manifest her will and to have her speak would not solve that inside the humble resources and formats on which I was dependent.

\section{Driving forces: Feminism and the gaze}

Picking up on the idea of Qvam looking back at me, it was a natural progression to think about her looking at us through time and space. Rather than thinking of the projection as a portrait of a historical person for us to look at, I started to imagine the gaze turned the other way around; her eyes looking back at us becomes an expression of willpower and the energy she must have had in order to change what she saw around her. What if in being projected on a prominent wall in the main square of her hometown, Fredrikke Qvam could look back at us, symbolically? The time span between her lifetime and the contemporary encompasses the drama of the Second World War. The town she had known was bombed and ruined; today the square is lined by modernist buildings from an optimistic and heroic period of rebuilding in the 1950s and 1960s. Not that long after she passed away in 1938, at the 
age of 95, her hometown was fundamentally changed. Might the people have changed as well? Where is our will to engage with the most vital problems of our times? No longer a mere historical biography of an outstanding individual, her background, biography, and achievements seemed to form a legacy, or a will of their own to bring forward.

My thoughts were supported by ideas from feminist film theory, such as Laura Mulvey’s triangle of gazes: the first is the camera registering the pre-filmic event; the second is the audience as they view the final product; and the third is how the protagonists look at each other in the illusory space of the movie narrative. According to Mulvey's analysis of the commercial narrative film, the gaze of both the audience and of the camera are denied and subordinated to the third. This prevents the camera from interfering and it keeps the audience from maintaining a critical distance, as Mulvey explained in Visual and Other Pleasures (1989). Moving the concept of the three gazes out of the commercial movie and into my studio, it provided the idea for building $F Q$ on a strategy that uses Fredrikke Qvam's gaze in front of the camera to connect with the audience instead of striving to build a narrative to be watched as a layer of constructed truth or biography. Returning to Susan Sontag, I found that the biographical pellets of information in the few photographs that formed the basis of this project, turned out to be less important than the clouds of fantasy emanating from them (Sontag, 1990 p. 69).

This was the point in production and reflection when the title of the project became " $F Q$ ", her initials rather than her name. This is where I could let my respect for my subject run free of an imagined obligation to present a full truth and take the permission of Barthes' four image-repertoires at work in portrait photographs to imagine who she was and to use her as a means to present my contemporary perspective on her. This is where I had to break through the documentary framework to let an artistic vision and interest guide the process. So far, I had worked in a documentary mode, doing research similar to that of a journalist. However, as soon as I started to influence and change the material, there were other methods and thoughts at play. I could no longer trace the process clearly through the blog; the work had taken on a sense of urgency where everything had to be tried out and reworked as animated images directly within the timeline of my editing. This was where the actual animation started to happen.

\section{Post-production}

The animation was four minutes long; it included a montage of diverse backgrounds, small embedded films or animations, and transient versions of the portraits. The composition is built on first presenting Fredrikke Marie Qvam as a silhouette on the wall and then letting her gaze float over the façade. The gaze gradually changes in time from that of the portrait of her youth into that of the older gaze. Then follows tableau-like scenes, representing the different phases in her life: as a mother, as an organizer, 
as a woman of strength and posture, and then it ends with a portrait of her in old age, averting her eyes at something beyond us. Throughout the process, I was attempting to include or make room for the architecture of the façade in the video piece. This does not mean that the animation is dependent on that particular façade, but it is constructed to encompass the prominent architectural features that were visible there at the time. One example is the motto of The National Health Organization for Women, which is the only text in the work. The text was initially composed to be projected onto the church wall, as a sign. In my translation from Norwegian, it reads:

In all things love

In big things unity

In small things freedom

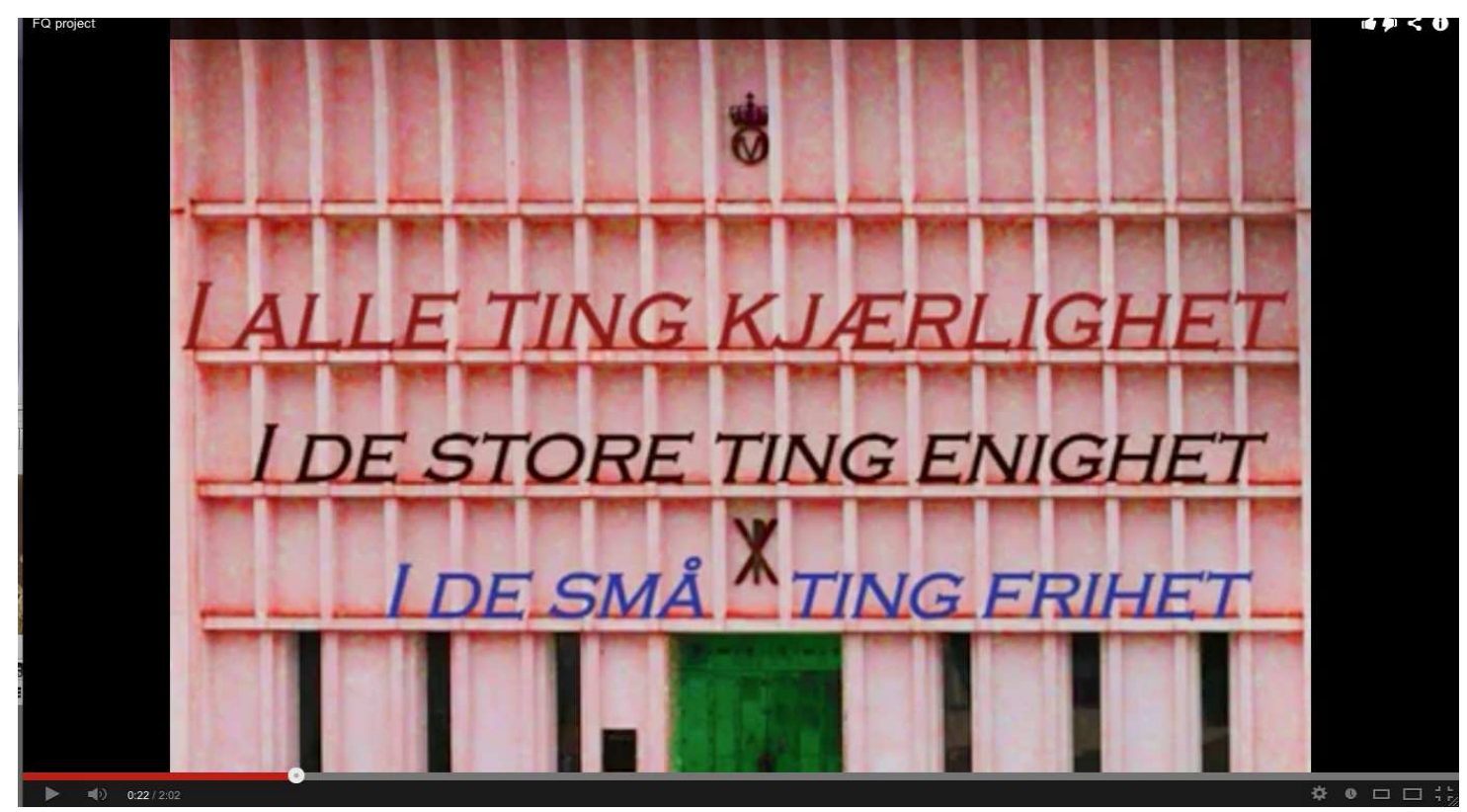

However, the technical specifications of the viewing situation made it unpredictable whether I could achieve the accuracy that this strategy demanded, and I had to employ a more free-floating composition to allow for flexibility in projection format.

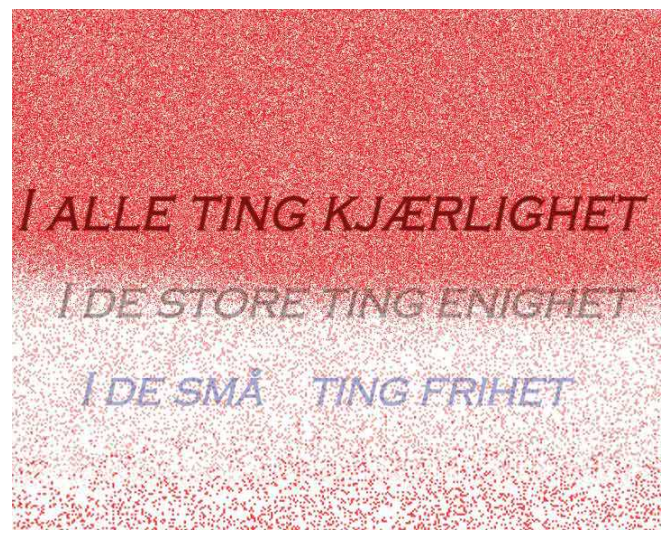

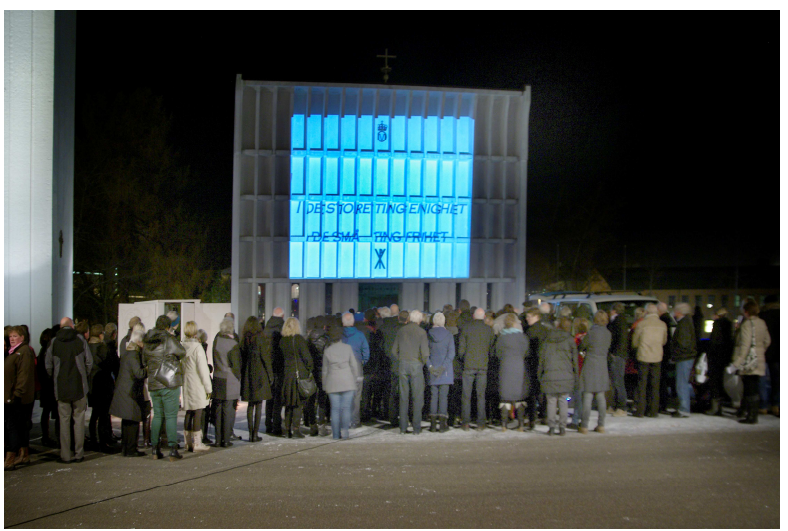


Working with projection frequently means working with an unstable format. There can be a tremendous difference between the post-production studio type environment, where the work is viewed on a monitor, and the actual on site projection. Although the technical quality of the projector and its positioning are both important, the local lighting conditions also influence the final outcome. To guard the work against difficult viewing conditions, which I could not fully control, I chose simplified graphic visual expressions that did not require too much detailing. After finishing the long slow process of putting the images together, I started to develop the sound to fit the images and the viewing situation. Sound is vital to anchoring a projection in a certain space, and in this instance, I literally based the sound work on the soundscape of contemporary Steinkjer. I collected sounds from around the square were $F Q$ was to be projected; I also recorded atmospheric sounds in the farms where Fredrikke had lived. The collected sounds included natural sounds from water, wind, birds, and human movement, as well as mechanical sounds from cars and trains; they were all used in the composition of the underlying score for the images.

At the end of my process of adding images, animations, and sounds, I carried a DVD looping four minutes of content out into the town square in Steinkjer to confront it with a viewing situation and an audience.

\section{Projecting and viewing}

In a sense, $F Q$ was adapted to a local context, a viewing situation that also had practical and technical limitations. The work can be said to be site specific or situation specific in other ways (Kwon, 2002), namely through the strong connection between the subject matter, Fredrikke Marie Qvam, and her hometown. The idea of turning her gaze to the audience, the notion that she would look at her hometown and its people assembled in the square, had a quality of intervention about it during its first presentation. The $F Q$ projection was not introduced, but as the audience was waiting for the opening ceremony of the Hilmar Festival, it suddenly appeared on the wall. Just beside the church, there is a bronze portrait bust of Fredrikke Marie Qvam. The audience in the square on November 8, 2012 immediately recognized her portrait on the wall. I heard them mumbling her name to each other, probably unthinkable in any other community. The medium of projection itself has an interesting effect when it is lighting up and changing a well-known architectural element. Since the projection, in itself, is nothing but light, it evokes the ephemeral quality of being in a transient state that affects something everyday and well-known. The projection is simultaneously an intervention and a communicative act, demanding attention by visual dominance. That the biographical background is known and recognized by the audience is an important factor in how the work has been received locally. In a sense, the documentary content, the fact that Fredrikke Marie Qvam was the subject, and 
the coincidence of the anniversary of women getting the right to vote in 2013 , all became significantly stronger factors in the project than I had originally anticipated and the video work has been shown repeatedly in this context in Steinkjer.

\section{Afterthoughts}

Looking back at the production process for this video project, I attempted to identify what came to be a mix of references and permissions taken as a means of creating $F Q$. Although the permission to follow what pricks you, a quality in the image that is reminiscent of Barthes punctum, something not possible to fully explain, and the freedom of a transient practice as described by Bull, are both factors that seem fundamental, this can only be played out when there is a collection of material to react on in an early phase of a project. The initial research of FQ, in addition to providing this material, also produced a biographical and historical context that helped form the foundation of the piece, as an archive of both visual and written information. As the formation of a tentative, conceptual, and aesthetic framework influenced the making of the video work, my focus turned to the potential expression of a social and personal attitude in the documentary material. Rather than a biography, the material inspired a collage around core phenomena in Fredrikke Marie Qvam's life, as we can imagine it today.

Since it will always represent something outside of the artistic realm, the use of documentary material leads to the necessity of a framework, a situation that can be described as a fluctuating relationship between research, art and audiences. This is an experience that is echoed in writer Umberto Eco's thoughts about "the work in movement", which figures in his essay on the open work from 1962:

The poetics of the work in movement (and partly that of the open work) sets in motion a new cycle of relations between the artist and his audience, a new mechanics of aesthetic perception, a different status for the artistic product in contemporary society. It opens a new page in sociology and in pedagogy as well as a new chapter in the history of art. It poses new practical problems by organizing new communicative situations. In short, it installs a new relationship between the contemplation and utilization of a work of art. (Eco, 2006 p. 39)

From my understanding, more than fifty years ago, Eco pinpointed an art that is not primarily autonomous but that reaches out in an attempt to open and react on an interdisciplinary field, both as aesthetic perception and reception. In this process, communication is a focal point to work on, a factor that should perhaps be inherent in the artwork itself, as has become customary during the last twenty years. The idea of the poetics of the work in movement can be re-imagined and re-worked in our time to become a productive tool for artists to construct frameworks that enable rigor as well as fantasy. 
Evoking the quote from Susan Sontag to summarize what became the most important qualities of working with historical photographs: They are clouds of fantasy and pellets of information. In my experience, documentary material represents information, both as a contextual background and as a more concrete rendering of looks and representations. This comes as no surprise, while the potential in art practice to let imagination and actualization create contemporary aesthetic reflection based on the same material, is probably less formulated.

A link to the video projection of FQ in Steinkjer:

http://youtu.be/XsVxkhA-Ko0

\section{On the contributor}

Kristin Bergaust graduated from the University of Oslo, Norway in 1983 and The National Academy of Fine Art in Oslo 1991. She was the director of Atelier Nord medialab for artists 1997-2001 and an active artist, curator and organizer in the field of socially conscious media, technology and art in Norway and elsewhere in Europe. From 2001 she was Associate Professor at Trondheim Academy of Fine Art, Faculty of Architecture and Fine Art, NTNU Norwegian University of Technology and Science, she held a full professorship in fine arts with a responsibility in Intermedia from 2003. In 2008 she became a professor at the Department of Art, Design and Drama at Oslo University College (now Faculty of Art, Design and Technology at Oslo and Akershus University College of Applied Sciences). Her artistic practice spans from individual gallery presentations to collaborative projects.

\section{References}

Barthes, R. (1993). Camera lucida. London: Vintage.

Bull, S. (2010). Photography. London and New York: Routledge.

Eco, U. (2006). The Poetics of the Open Work//1962 In C. Bishop (Ed.) Participation. Cambridge, MA: MIT Press.

Kwon, M. (2002). One place after another. Cambridge, MA: MIT Press.

Merewether, S. (Ed.). (2006). The archive. London: Whitechapel.

Sontag, S. (1990). On photography. Picador, New York.

Bergaust, K. (2012)Research Blog http://kbergaust.wordpress.com/ consulted 13.03.2013

Fredrikke Marie Qvam. Norske Kvinners Sanitetsforening http://www.sanitetskvinnene.no/no/om_nks/historikk/fredrikke_marie_qvam 13.03.2013

Bergaust,K. (2013) Homepage http://www.kristinbergaust.no 13.03.2013 